\title{
TEORIA DE LOS GASTOS DE LA ADMINISTRACION LOCAL
}

\section{A) La necesidad local.}

El complemento necesario de la Hacienda estatal es la Hacienda local: la de las provincias y la de los municipios, particularmente la de estos últimos, pues sin municipios no puede el Estado moderno realizar sus funciones. Es por ello que los tratadistas de Economía financiera o Hacienda pública dedican siempre un capítulo especial a las Haciendas locales, abordando el problema de la relación de éstas con la estatal, condicionado siempre por la posición del Municipio frente al Estado. Porque, en efecto, esos tres órganos se reparten las diversas funciones que la autoridad pública ha de realizar en interés de la vida nacional. Pero se cometería un error suponiendo que el límite entre la tarea atribuída al Estado, la que incumbe a la Provincia y la que está reservada al Municipio, puede ser establecido de una manera categórica.

Y no solamente no puede establecerse ese límite de forma clara y perfecta, sino que es también imposible respetar en todo momento el que se hubiere fijado. Sin embargo, con frecuencia se ha dicho que es completamente necesario repartir de forma racional y lógica las diferentes funciones que incumben a los órganos encargados de regir la vida púbilica; pero que al propio tiempo es inevitable que en la ejecución de sus respectivas misiones se presenten ocasiones en que la actividad de uno de esos órganos se confunda con la de otro. Empeño vano el de pretender definir y. limitar, de manera precisa, el papel de cada autoridad, para obtener así de su actividad un mayor rendimiento.

Cualquiera que sea la idea que nos hagamos de la ciudad, del $\mathrm{Mu}$ nicipio y de sú función en la época actual, correlativa al criterio de centralización o de autonomía más o menos amplia, es evidente que las atribuciones que el Estado debe conceder a la Provincia y al $\mathrm{Mu}$ nicipio en el conjunto de la vida pública social deben ser de tal natu- 
raleza que les posibiliten el cumplimiento de la labor que les está encomendada. El Estado se ha reservado siempre todas las misiones que afectan al conjunto de la Nación. A él incumbe: el deber de cuidar de los intereses económicos y políticos en general; la tarea de señalar todas las medidas que conduzcan al progreso moral y material del país; aquellas que requiere la protección de la salud pública, las que atañen a la instrucción, a la defensa nacional; las medidas necesarias para crear y mantener la seguridad del ciudadano, tanto desde el punto de vista de la protección de su persona como del de la de sus bienes, etcétera, y el derecho general de inspección y control sobre las Corporaciones locales, de especial aplicación en el campo de la Hacienda; fiscalización que se va transformando en verdadera tutela, sobre todo en los países de régimen totalitario.

Como entidades territoriales, las provincias y los municipios resultan impuestas por la forma de distribución geográfica de la pablación. Tanto en las zonas urbanas como en las rurales, la población se agrupa formando unidades compactas en el centro de una extensión territorial, donde los agrupados desarrollan sus actividades. Destaca aquí la ciudad, centro donde se ejercen y se confunden todas las actividades-del hombre moderno; en ella se educa, trabaja, se recrea, busca asistencia; es donde la cooperación humana se ejerce bajo todas las formas y donde encuentra su más completa y amplia expresión en un conjunto de instituciones y servicios organizados por la colectividad en beneficio de todos sus miembros. Cada una de esas unidades demográficas plantea exigencias que interesan de modo inmediato a la vida de los agrupados: tales son los servicios de carácter local.

En este problema influye también le un modo decisivo - como en todas las cuestiones de tipo administrativo o económico- la ley de la división del trabajo. Pues si el Estado hubiese de atender directamente todos los servicios, los de carácter genuinamente local, que interesan más directamente a los vecinos en cada ciudad o Municipio, tendrían que ser forzosamente postergados ante la exigencia más apremiante de problemas de significación auténticamente estatal. Para los agrupados en un Municipio la urgencia de dar solución a problemas como los de abastecimiento de aguas, beneficencia, alcantarillado, pavimentación, etc., resulta de igual modo vital como la defensa del propio Estado, porque afectan a su existencia. Esos problemas, de otra parte, pueden diferenciarse de los generales o nacionales por el área sobre la que extienden su interés: las dimensiones respectivas de cada uno determinan su naturaleza estatal o local. 0 bien, 656 siguiendo el principio económico y relacionándolo con el problema de 
la distribución de los deberes públicos, podría decirse que en este reparto ha de buscarse el máximo provecho y el mínimo de daño social.

El interés es, según Karel Englis, el primer criterio para la distribución. Cuando se cruzan los intereses decide el interés superior. Una corporación superior puede asumir el deber de una corporación inferior, aunque ésta se halle más directamente interesada en él. El deber que se confía a una corporación inferior depende, al mismo tiempo, de su capacidad. Puede haber intereses que, según su carácter, son locales, pero cuya realización homogénea en todo el territorio nacional presente un gran interés, de manera que no se pueden admitir las disparidades que resultarían de las diferentes capacidades. La instrucción de la infancia - continúa diciendo Englis- constituye una misión local, que es paralela a la de los demás municipios en la nación, pero todavía no es común por esta razón. Si se confiara enteramente a los municipios, se realizaría de una manera muy desigual, porque muchos de ellos ni podrían sostener a un maestro calificado; pero la igualdad de la enseñanza primaria es de un interés nacional. No basta únicamente ordenar a los municipios que cuiden de la instrucción de la infancia, si no tiene medios para ello; por esta razón, las corporaciones superiores asumen el coste que es indispensable para la realizáción homogénea de este interés. El interés natural (local) subsiste como criterio de distribución, únicamente cuando no interfilere con un interés superior que tienda a ia realización homogérea de un cierto deber, que podría queảar amenazado por la diferente capacidad de las corporaciones locales.

No olvidemos que los problemas locales no son, por lo general, sino problemas reflejos de los que personifica el Estado: Hasta tal punto no lo olvidamos, que somos partidarios de una fuerte inspección sobre las Haciendas locales, ejercida constante y directamente por èl Ministerio de la Gobernación. Pues, en nuestra opinión, el concepto de autonomía ha de constreñirse a una amplia libertad de iniciativas controladas por los órganos estatales. Esas iniciativas han de dirigirse siempre a servicios o funciones que acusen un interés primario para los componentes del grupo, y que la ley debe definir y catalogar.

Llegamos de esta manera a la formación del concepto de necesidad local, que podemos definir como "aquella necesidad, individual o colectiva, que se satisface por una Administración local, en virtud de sus funciones de cooperación a los fines del Estado", cuyo número e intensidad dependen de la solución que en cada país y en cada momento histórico se dé a la cuestión del reparto de las funciones públicas entre el Estado y las entidades locales. En el preámbulo del Es- 
tatuto provincial de 1925 encontramos el criterio del legislador de entonces para distinguir los dos grados que en nuestro país se advierten en la necesidad local. Los fines esenciales de la provincia "deberán ser todos aquellos de índole local que, rebasando las posibilidades de la acción municipal, escapen a la jurisdicción de cada Ayuntamiento". No serán, pues, fines específicamente distintos de los que constituyen la exclusiva competencia municipal; pero sí superiores -en extensión, en entidad y en coste-a estos últimos; en definitiva, "serán fines y servicios de enlace intermunicipal para el complemento y perfección de los propios organizados por cada Corporación comunal". Todo cuanto se califica como de la competencia provincial - Beneficencia, Sanidad, Comunicaciones, Cultura-es también atribución propia de los municipios: la diferencia está en el grado, en la órbita. Tales servicios son de índole local, tanto al prestarlos el Ayuntamiento como al regirlos una Dr̃putación. Esta ,en realidad, se limita a organizarlos cuando por su radio territorial o coste sobrepasan las posibilidades jurisdiccionales o pecuniarias de las Corporaciones municipales.

\section{b) Gastos obligatorios y facultativos.}

A la palabra necesidad corresponde la idea de fines, y, en definitiva, la de gasto, pues entre estos términos media una evidente inteligencia, ya que no se concibe ningún gasto que no implique una necesidad, ni necesidad que no se halle determinada por un fin. Toda actividad administrativa del Estado y de las Corporaciones locales se traduce en gastos públicos y necesita de recursos econọmicos. Es decir, que los gastos legitiman y justifican los ingresos, pero ha de establecerse siempre la debida relación entre los deseos de la Hacienda local y sus posibilidades económicas.

La economía, el ahorro, es el principio supremo del gasto; mas con ello no se quiere decir que deba renunciarse a la satisfacción de las necesidades colectivas, ni que merezcan mayor consideración las Haciendas locales que menos gasten. No se debe ahorrar o economizar cuando con ello queden indotados servicios importantes, necesarios o útiles; antes al contrario, la Hacienda mejor organizada será aquella que atienda en forma eficiente a todos ios fines necesarios o útiles. Claro es que.cada nuevo gasto debe ser estudiado desde el doble punto de vista de su necesidad o utilidad y de su urgencia, no considerándole aisladamente, sino en comparación con la ya existente. 658 Es gasto admisible, por lo general, aquel que, directa o indirectamen- 
te, venga a acrecentar la potencialidad económica de la Provincia o Municipio - de la Nación, en definitiva- y rinda beneficios a la colectividad. Los consumos necesarios, siempre que sea posible, deben efectuarse en la propia localidad. No hemos de tratar aquí de la reproductividad del gasto, ni de otros principios económicos, reduciéndonos por ahora a definir sus diversas categorías.

Se ha dicho que la potestad financiera del Estado no reconoce límites; que el Estado puede acomodar los ingresos al gasto, mas indudablemente existe un límite teórico que algunos autores han tratado de fijar matemáticamente, si bien, en definitiva, como dice Griziotti, "nada puede afirmarse de un modo preciso a este respecto". El caso de las Haciendas locales es muy distinto, pues sus gastos dependen, principalmente, de su mayor o menor desenvolvimiento económico, de los medios que puedan disponer y de que el Estado haya delegado en ellas más o menos obligaciones, el cumplimiento de más o menos fines. Realizan gastos obligatorios y gastos facultativos; entre los primeros, hay gastos que no responden a una necesidad local, sino a conveniencias prácticas, y gastos inherentes al cumplimiento de los fines propios de las entidades locales. La obligatoriedad de los gastos deriva, en ambos casos, de un acto de soberanía del Estado, que los impone con referencia a funciones, obligaciones o fines cuyo cumplimiento delega en las Diputaciones y Ayuntamientos, y esa obli. gatoriedad puede tener tres grados, a saber:

a) El Estado impone a las entidades locales la realización de determinados servicios o prestaciones, con el carácter de obligaciones mínimas, sin limitar, por lo general, la cuantía del gasto.

b) En otras ocasiones, el Estado señala la suma exacta o cuota que han de satisfacer para el sostenimiento de determinados institutos o servicios públicos; y

c) Finalmente, para ciertas categorias, el derecho positivo fija, bien un límite máximo, bien un mínimo, en relación con el total importe del presupuesto ordinario de la entidad local, atendiendo siempre a la importancia del grupo social de que se trate.

En todos los países, al lado de estos gastos obligatorios figuran otros de carácter voluntario, porque las entidades locales están autorizadas, siempre que dispongan de los medios necesarios, para crear instituciones $\mathrm{y}$ establecimientos destinados al fomento materíal y espiritual de los vecinos, con tal amplitud que no les está vedada su actuación en ningún aspecto que afecte al ciudado del bienestar. Pero es natural que el Estado no permanezca ajeno a ese círculo de actuación voluntaria, pues no es tolerable que en beneficio de 659 
ésta se desatienda el cumplimiento de las funciones mínimas obligatorias o que se apele con exceso a la capacidad de protección de los ciudadanos.

Lo que confirma, según Jéze, la estrecha conexión existente entre los servicios nacionales y locales, es la diversidad de las soluciones admitida en la legislación positiva: ciertos Estados hacen de algunos gastos, gastos nacionales, y de otros, gastos locales; muchas veces se forman gastos mixtos, soportados a la vez por el Estado y las localidades, y aun en un mismo país, la clasificación varía según las épocas. Del constante incremento de los gastos forzosos, parece que habría de derivarse una doble consecuencia: $1 . \therefore$ la intensificación del derecho de inspección o de control, y 2:", la concesión de grandes subvenciones. Mas es cierto que muchas veces sólo se ha obtenido la primera consecuencia, pues la ayuda del Estado no ha tenido la importancia que sería de desear, dādo el enorme desarrollo de tales gastos. Algunos han creído ver aquí una manifestación de descentralización administrativa, lo que es un error, pues el servicio no llega por eso a ser local, sino que está dirigido por el Estado, siendo, ante todo, un desplazamiento de gastos.

\section{c) Otras clasificaciones.}

La distinción de los gastos en permanentes y temporales responde a una clasificación de los servicios públicos, que es independiente de la cuantía del gasto. En las leyes suelen considerarse como servicios o gastos de carácter permanente los que se refieren a fines esenciales, aunque su cuantía sea variable; por el contrario, los servicios y gastos no duraderos, aunque su crédito sea fijo, se llaman temporales. Trátase de una distinción puramente administrativa, aunque necesaria, para la formación de los presupuestos. Entre los servicios de carácter permanente se comprenden: a) todos los gastos de personal; b) los de escritorio o material ordinario de oficina, $\mathbf{y}$ c) los gastos diversos que no se refieren a material ordinario de oficina ni a personal.

Por otra parte, se distinguen también los gastos administrativos, es decir, los que directamente se emplean en la satisfacción de las necesidades de la entidad pública, de los gastos de explotación que se ocasionan por la percepción de los ingresos.

Los gastos de personal se refieren a la compensación y pago de servicios prestados a la entidad pública, consistiendo en sueldos, pen660 siones, salarios, gratificaciones, gasto de representación, viáticos, 
etc. Los servicios públicos requieren una especialización en los funcionarios que sólo se adquiere mediante una preparación costosa que debe ser bien remunerada, y además, la carestía de la vida sigue una progresión ascendente que origina la necesidad de aumentar los haberes de los funcionarios. Los gastos de material responden a la llamada "necesidad real", es decir, a la necesidad que la entidad local tiene de adquirir los bienes materiales precisos para el cumplimiento de sus fines.

En las Haciendas locales podemos distinguir también, con Pigou, entre gastos consuntivos, que representan un consumo real y eîectivo de riqueza, y gastos traslativos, que sólo implican la transferencia de ésta, pues para una y otra categorías son adecuadas fuentes particulares de ingresos. Diferénciase también los gastos productivos de los improductivos, aunque más modernamente se hable solamente de gastos reproductivos.

\section{d) Gastos ordinarios y extraordinarios.}

Es fundamental para la técnica de Presupuestos la separación entre gastos ordinarios y extraordinarios, acerca de los cuales parece obvio indicar que los primeros son los que se repiten de una manera regular, constante y periódica en cada ejercicio económico, aunque experimenten un paulatino crecimiento. Por el contrario, se estiman como extraordinarios aquellos gastos irregulares o imprevistos que se producen una sola vez o en períodos muy variables, sin sujetarse a una ley fija. Entre unos y otros suelen colocarse los gastos contingentes, que surgen cuando las necesidades se presentan sin una frecuencia regular y se efectúan una vez, sin que por su cuantía excedan de los límites prudenciales del gasto ordinario. La técnica moderna rechaza aquel viejo principio, según el cual los gastos ordinarios se cubren con ingresos ordinarios; los extraordinarios, con recursos excepcionales. Según Griziotti, a los gastos ordinarios se provee normalmente con ingresos ordinarios, que siguen las mismas leyes de desarrollo del gasto. Pero cuando no sean suficientes las fuerzas económicas del país, por crisis y otras causas excepcionales, para soportar la carga de los gastos ordinarios, es lógico recurrir, aun para gastos de carácter permanente (continuo) a ingresos extraordinarios, que pueden provenir, ya de la enajenación del patrimonio público, ya de la apelación al crédito. A los gastos extraordinarios se puede también proveer de doble modo: con ingresos ordinarios, o con ingresos extraordinarios. Si los gastos extraordinarios - sigue di- 661 
ciendo este autor - no son relevantes, y, sobre todo, cuando ofrecen ocasión de renovarse en medida y periodicidad variables, es oportuno que satisfagan con ingresos ordinarios, siempre que se contengan dentro de los límites de la potencialidad económica nacional, a que de continuo puede apelar el Estado para hacer frente a las necesidades públicas. Cuando sobrepasan estos límites, deben satisfacerse con ingresos extraordinarios.

La teoría puede aplicarse a las Administraciones locales, en términos mucho más reducidos y en la forma siguiente:

A) Todo gasto ordinario debe ser cubierto con ingresos normales.

B) Todo gasto extraordinario, mientras sea posible, debe serlo también con recursos permanentes.

C) En defecto de los ingresos normales, ha de acudirse, tanto para atenciones ordinarias como extraordinarias, a los recursos extraordinarios.

Apartándonos del Derecho positivo, es indudable que todos los gastos pueden aparecer mezclados en una misma relación de conceptos; la contrapartida de ingresos puede ser única o estar diferenciada. Todo ello "es un problema de forma y de método que, salvo circunstancias excepcionales, debe ser resuelto siempre aplicando el criterio de la separacion, el cual no implica precisamente ausencia dz cánones en la selección de la cuantía de los gastos ni en el orden de proceder". (De la oxnngición de motivos de la Ley de 21 de junio d*. 1940, aprobatoria del presupuesto extraordinario de gastos del Estado esnañol.) Mas si para el Estado es posible la discusión, e incluso que un presunuesto extraordinario aparezca como suplemento del ordinario en cuanto a gastos, teniendo como contrapartida los recursos normales, porque la Ley de Administración y Contabilidad de la Hacienda pública guarda silencin sobre el particular-ni siquiera en ella se citan los presupuestos extraordinarios_, tratándose de las Haciendas locales la rigidez de la norma jurídica excusa todo debate, pues en los Estatutos y en \&l Reglamento de Hacienda municipal se concretan:

a) los gastos que pueden contener los presupuestos extraordinarios; b) los recursos extraordinarios que pueden imponerse, entre los cuales destaca la contratación de empréstitos, y c) la estructura y tramitación del presupuesto (extraordinario) en que unos y otros 662 deben reflejarse. 


\section{e) Evaluación del gasto.}

¿Cómo evaluaremos los gastos? Siendo el equilibrio entre gastos $e$ ingresos absolutamente necesario, es preciso que tanto unos como otros estén previstos y evaluados con la mayor exactitud posible. Por experiencia saben los Interventores de Fondos que a veces el déficit ha tenido por causa la exageración de las partidas de ingresos, la omisión de ciertos gastos que han podido preverse o la restricción de su montante probable. En circunstancias normales es muy raro que el déficit provenga de circunstancias absolutamente imprevistas. Es por esto que las cualidades personales de los preparadores del presupuesto, su sinceridad y perspicacia juegan un papel muy principal. "El equilibrio presupuestario-ha dicho Jèze-se obtendrá por la sinceridad del que lo prepara, y los métodos no significan sino una ayuda." De una manera general, para los gastos podrían enunciarse las siguientes reglas:

1. El importe de cada gasto en el último presupuesto liquidado (consuntivo) es el primer elemento de cálculo para los futuros (regla del penúltimo año).

2. Las previsiones serán tanto más exactas cuanto más próximas estén al ejercicio de que se trate.

3. El optimismo conduce al equilibrio sobre el papel, no al equilibrio real. Si se quiere ser sincero, no se debe ser optimista.

4. Lo más seguro será atenerse a los hechos conocidos, sin mejorarlos si no en la medida que permita o aconseje una buena situación de Tesorería (un superávit efectivo, no ilusorio, que se haya mantenido en varios años).

5. Nunca debe cifrarse una partida por su importe neto (regla del presupuesto bruto).

6..$^{\circ}$ Todo gasto, por insignificante que sea, debe aparecer relacionado (principio de la generalidad).

7. La necesidad de efectuar alguna transferencia durante el ejercicio debe ser considerada como una calamidad. Teóricamente al menos, las transferencias no deben ser posibles.

8. Una buena clasificación, por capítulos, artículos, grupos, confección de los presupuestos' ordinarios, es del mayor interés, por ceptos y partidas, facilitará extraordinariamente la ejecución del presupuesto (principio de la especialización).

La Orden de 15 de noviembre de 1940 dando normas para la confección de los presupuestos ordinarios, es del mayor interés, por constituir la refundición de las disposiciones aplicables. La Direc- 
ción general de Administración local la viene recordando todos los años, habiéndolo sido para el ejercicio de 1943 por Orden circular de 31 de octubre de 1942. En ellas han de inspirar su conducta los Interventores, principalmente en materia de gastos, en la norma que dice: "El avalúo de cada partida de gastos se calculará por el promedio de las resultas que el servicio arroje en la liquidación de los últimos presupuestos que se hayan desarrollado con normalidad, acomodándose a las necesidades presentes en cuanto sea posible".

Antonio Saura Pacheco

Psofesor de la Escuela Naciu nal de Administracion. y Estudios Urbanos. 